\title{
An analysis of the old age security management of flexible employees
}

\author{
Li Shuang ${ }^{1, a^{*}}$, Jin Daizhi²,b \\ ${ }^{1}$ of Affiliation: ${ }^{1}$ School of Finance and public administration, Harbin University of Commerce, No.1 Xuehai street, Songbei District, Harbin \\ City, Heilongjiang Province, China \\ ${ }^{2}$ of Affiliation: ${ }^{2}$ School of Finance and public administration, Harbin University of Commerce, No.1 Xuehai street, Songbei District, Harbin \\ City, Heilongjiang Province, China
}

\begin{abstract}
With the increasing number of flexible employees, the related security issues of flexible employees are becoming a topic of concern. It has been put on the agenda to strengthen the management of medical, industrial injury and unemployment security of flexible employees, but the management of pension security still faces many problems. This paper analyzes the two aspects of the system factors and human factors existing in the old-age security management of flexible employment personnel, and puts forward corresponding suggestions.
\end{abstract}

\section{Research background}

With the rapid development of economy and society, the labor demand of large developed cities in China is expanding, the industrial industrial system is constantly improving, the demand for labor is increasing, and the network is developing. New flexible employment modes such as online car, take-out and host appear. From the original labor relationship with the original unit to the current independent employment, it should be completed by the previous university The proportion of the graduates engaged in the self-employed is higher and higher. ${ }^{[1]}$ Flexible employment is relatively open. The relevant research of the Ministry of labor holds that the concept of "flexible employment" refers to the employment modes which are different from modern industry and factory system in terms of labor relations, labor time, salary and remuneration, and security welfare, etc. ${ }^{[2]}$ In a word, flexible employment has the following four characteristics: (1) there are no labor contracts signed, no labor relations with enterprises; (2) the way of livelihood is more flexible and part of them can be engaged in for a long time; (3) the time and city where the labor services are provided are generally determined; (4) the rules and regulations to be followed for the provision of labor services are not completely fixed. ${ }^{[3]}$

At present, due to the lack of relevant labor contract, flexible employment personnel have caused the absence of medical care, industrial injury, pension and other aspects, which leads to the reduction of the national welfare and the

\footnotetext{
${ }^{[1]}$ Zhao Yujiu. (2020) Discussion on basic endowment insurance for flexible employees [J]. Labor security world, $55+60$.

${ }^{[2]}$ Research Report on flexible and diversified employment forms issued by Institute of labor science, Ministry of labor and social security (2002).

a* Corresponding author: 13613626038@163.com

be-mail:213613626038@163.com
}

worries of the relief. The resulting social injustice, from the perspective of social development, is not in line with the essential characteristics of socialism in China, but also easily causes social contradictions to intensify, aggravate the gap between the rich and the poor, and affect the social stability. With the decline of the population dividend in China, the aging degree of the population in China is relatively high. The flexible employment personnel still stay in the work position, and have begun to consider the payment of 15 years of pension insurance, so the pension security of flexible employment personnel will be further expanded. At present, the research on social security mainly focuses on the medical treatment, work injury and unemployment of flexible employment personnel. At present, there are few researches on pension security for flexible employment personnel. Therefore, it is necessary to further strengthen the research on this aspect.

\section{Problems of flexible employment personnel participating in pension security}

The pension security of flexible employment personnel is faced with two aspects: system level and human. In summary, it is the problem of "not want to pay, cannot pay, how to pay".

\subsection{Institutional issues}

\subsubsection{The burden of endowment insurance payment}

\footnotetext{
${ }^{[3]}$ Li Haiming, Luo Xunyang. (2019) Protection of the rights and interests of flexible
} employment under platform economy [J]. Innovation, 108-118. 
is too heavy: The Ministry of human resources and social security of the people's Republic of China stipulates that when selecting the payment base, there is a range limit of $60 \%-300 \%$ of the full caliber average wage of the urban employees in the last year. In this range, the payment base level is selected, and the payment proportion is $20 \%$ of the flexible employees. At present, according to the survey, the average monthly income of flexible employees is 5808 yuan..

Table I.average wage of employees in Urban Units

\begin{tabular}{|c|c|c|c|c|}
\hline Year & 2015 & 2016 & 2017 & 2018 \\
\hline $\begin{array}{c}\text { Average wage of } \\
\text { Urban Units }\end{array}$ & 62029 & 67569 & 74318 & 82413 \\
\hline
\end{tabular}

Source: China Statistical Yearbook

Table I shows that the average urban wage in 2018 is above 800000 yuan, much higher than that of flexible employment personnel. Meanwhile, the proportion of payment base of flexible employment personnel is still $20 \%$ while the insurance expenses of enterprises are reduced by the state, and only $8 \%$ of them enter into personal accounts. The income of flexible employment personnel can not support their basic living expenses, the expenses of children education, medical treatment, work-related injury, unemployment and pension insurance, which leads to flexible employment personnel can only suspend a part of social security plan indefinitely.

\subsubsection{Insufficient publicity and service of old age} security: At present, due to various factors, the number of service windows and service personnel is not enough to meet the basic needs of relevant service institutions, which leads to the long-term waiting for the persons handling or consulting, and the difficulty of refinement and personalization of management services; because the original flexible employment personnel have not a high understanding of the relevant pension security policies, the government cannot be realized due to various restrictive factors The application of notice of arrears and base improvement notice makes flexible employees have a non willingness to pay for the pension security, and the flexible employment personnel do not trust the social pension security. ${ }^{[4]}$ At present, the propaganda of the main social pension security in China still stays in the traditional ways of window service, the government distributing the relevant knowledge pamphlets and the brief news reports, and the scope of publicity popularization is not ideal. Because flexible employment personnel themselves do not fully understand the relevant system of social pension security, the lack of understanding leads to the distrust of social pension security and the inadequate service of

[4] Liu Xianqing. (2019) Research on the current situation and Countermeasures of social insurance work for flexible employees -- Taking Pingdu City as an example [J]. Science and technology economy guide, $213+212$.

[5] Zhao Yihong, Gao Shuang. (2019) Research on the current situation and Countermeasures of urban flexible employment personnel participating in social endowment insurance $[\mathrm{J}]$. China logistics and procurement, 78. relevant government, which leads to their preference for saving and pension. ${ }^{[5]}$

\subsubsection{It is difficult to continue the relationship of} endowment insurance: At present, the old-age security in some areas remains at the level of county and city level. Some developed areas are in the stage of gradual transition to provincial level. The national overall planning is the best solution recognized by the collective, but it is still difficult to turn it into reality. Moreover, the overall imbalance of China's economic development, the uncoordinated regional economic development, and the ever existing problems of China's relatively low level of social security For the serious structural problems of urban and rural areas and the restrictions of registered residence system, the differences of financial status in different regions are further widened, so the liability of old age insurance that they can undertake is different. Even the standard of collecting and paying the old age security in developed and underdeveloped areas is not consistent, and the cost of the transition of the old age security relationship becomes different again. ${ }^{[6]}$ At present, China's population flow is in the stage of flowing from economically underdeveloped areas to economically developed areas. In order to protect the basic interests of economically developed areas and reduce the expenditure of pension security funds that are generally faced with problems, it is not unreasonable to set up transfer barriers of pension security relations between regions.Although the current system of transferring pension relations in China has weakened the registered residence restrictions of urban residents participating in endowment insurance to a certain extent. The result is that the former paid fees of mobile workers are cancelled and recalculated, or because of the differences in the regional pension policy, the relevant procedures are different, and the transfer work becomes more complicated, resulting in the protection benefits they can get from the economic level of the local area, registered residence restrictions, policy differences and other factors.

\subsubsection{Lack of relevant legal protection of old age} security: The main protection object of the current endowment insurance law of China is full-time employees, which does not specifically explain the flexible employment and related personnel. Even some of the laws are also based on migrant workers and other special types of work, and even some of the contents are only suitable for several areas. Because there is no specific targeted legal protection, the legitimate rights and interests of a considerable number of flexible employment personnel can not be protected, even in the face of some violations of rights and interests, due to other reasons or economic factors, they can not be effectively protected. ${ }^{[7]}$ Moreover, the "social insurance law" on the "payment to the age of

[6] Shan Linlin. (2017) Analysis on the transfer of endowment insurance for migrant workers [J]. JOURNAL OF LIAONING TEACHERS COLLEGE (SOCIAL SCIENCE EDITION), 35-37.

[7] Xiang Chunhua. (2018) Is it illegal to allow flexible employees to pay endowment insurance premium [J]. China social security , 57. 
15 " provisions, for the "payment" of the specific way is not very clear. Although it has the meaning of "deferred payment" from its literal meaning, that is to say, the annual payment will be renewed until the end of 15 years, there are no clear provisions, such as the payment base, payment proportion, payment subject and so on, and it is not very sure how to pay in the end. In addition to the provision of "delayed payment", although some provisions express that one-time payment can be made if conditions permit, they do not specify the specific content of how to make one-time payment. It is unknown whether the payment is calculated according to the historical time or the future time..

\subsubsection{The problem of not being able to make up the} payment for older people: Because the flexible employment personnel's related endowment insurance policy formulation and implementation time is relatively late, and because of the insensitivity to the policy, the understanding of endowment insurance is not enough, and the timely understanding is not deep enough, many flexible employment personnel who want to participate in social endowment insurance have exceeded the legal age of insurance, and lost the right to enjoy endowment insurance, which is related to the expansion of endowment insurance coverage face to face is contradictory.

\subsubsection{Getting state subsidies is cumbersome: The} materials to apply for social insurance subsidies include: relevant certification materials, which should be signed by the person and sealed by the human resources and social security department, indicating the specific unit, position, address, etc., as well as the copy of the "resident identity card" and the "registration certificate", the registration certificate issued by the social insurance fund in the previous quarter and the proof of payment After being examined by the human resources and social security department and reviewed by the financial department, it will be issued to the applicant according to the regulations. ${ }^{[8]}$

\subsection{Human problems}

2.2.1 The characteristics of flexible employment increase the difficulty of security work: He first is the flexibility of their working hours and the instability of their working relationship. Even if some units are willing to pay for their old-age security, it will increase the difficulty of transferring old-age insurance because the working relationship may change at any time. The second is the income elasticity. The income of most of the flexible employees is far lower than the average wage level in the region. Under the price level, it is likely that it is only enough for basic living, and there is no idle funds to pay the endowment insurance premium at all; third, enterprises and institutions are more common to participate in the endowment insurance, if the unit is an individual, it greatly increases the complexity of participating in the insurance.

\subsubsection{Flexible employment unit is not willing to pay} endowment insurance: First, the current employment pressure is great, people in order to find a stable job, often do not dare to pay the endowment insurance premium to the unit; second, some individual and private enterprises excessively pursue economic interests, worried that paying the endowment insurance premium will affect the capital flow, affect production and operation.

\subsubsection{The contradiction of insufficient cognition of} endowment insurance policy: Some of them have a low level of education and do not fully understand the policy. They think that as long as they have paid for the endowment insurance for 15 years, they can enjoy the treatment of receiving the endowment insurance every month after they reach the retirement age. Therefore, they will stop paying after they have paid for the endowment insurance for 15 years. ${ }^{[9]}$

2.2.4 Low degree of organization: The lack of trade union leads to the strong dependence of flexible employees on employers. According to the labor law, employers can establish trade unions and other organizations for collective consultation and discussion, but the decentralization of employment opportunities reduces the stability of labor relations, which increases the difficulty of establishing trade unions for the flexible employees scattered in various places. Therefore, it is difficult to rely on collective organizations such as trade unions for rights and interests relief when rights and interests are infringed.

\section{Suggestions on the reform of pension security for flexible employees}

\subsection{Implement flexible multi-level old-age security}

The establishment of "personal development account" of flexible employment personnel follows the principle of "saving money first and then distributing". The owner of the account can save any amount of one or more security projects according to the time limit of the month, quarter and year, and then the fund operation management organization shall allocate the previous annual savings according to a certain proportion according to the insured items. And it is clearly stipulated that all the savings funds paid by individuals are included in their own personal accounts, the corresponding subsidy amount is included in the overall account, and the time limit and total time limit are set for the allocation.To improve the flexibility of payment period, under the condition that the overall planning of the whole country is not realized, the 
proportion of payment shall be appropriately changed according to the economic development of the region, from $20 \%$ to $18 \%$ to $15 \%$ in the past, and $2-5 \%$ down. This also eases the downward pressure of the economy and improves the enthusiasm of flexible employment personnel in paying.

\subsection{Further improve the connection of endowment insurance}

In the case of flexible employment personnel can provide relevant proof, the inflow of people from other places should be allowed to participate in endowment insurance as unrestricted as local people in this region. At present, the relevant documents that can provide proof should include: (1) residence permit, which can identify whether he has stayed in the local for a long time, so as to identify whether the flexible employment personnel has lived for a long time or maliciously insured according to the developed situation; (2) Street community can provide employment certificate. To further strengthen the city's grassroots management, community managers can better understand the community situation, so as to understand the employment situation of the transferred population; (3) individual institutions with industrial and commercial registration can also provide information on the working conditions of flexible employees; (4) retail and wholesale malls, farmers' markets or building properties can understand the situation of their own merchants, and can also provide their own information work certification of flexible employees in the region.

\subsection{Improve the relevant government work}

We should actively promote the payment method of bank entrusted deduction, reduce the number of round trips of insured personnel, simplify the payment procedures, and realize automatic payment; strengthen the supervision, focus on the inspection of cross region, cross industry, cross unit, and other places to ensure that enterprise employees can enjoy their legitimate rights and interests; the corresponding management and implementation agencies should give full play to their actual administrative rights In order to improve their service ability, we should strengthen the training of the professional quality and ability of the relevant government pension service personnel.

\subsection{Increase national support}

The emergence and persistence of the old-age security behavior of the flexible employment personnel, even if there is the internal cause of breaking the traditional concept of raising children for old age, also needs the external inducement of the national financial subsidies and payment incentive mechanism. Therefore, it is necessary to take the form of government subsidies to implement the policy of paying first and then making up for the flexible employees who have reached the age of 60 , so as to greatly improve the desire of the flexible employees to participate in the endowment insurance. According to the level of social insurance payment subsidy for the flexible employment personnel caused by dismissal, the payment subsidy is modified, and the corresponding level of payment subsidy is given to the flexible employment personnel such as individual industrial and commercial households who are facing continuous payment difficulties. Among them, the undertakers of all the expenses included in the individual account remain unchanged, and the part of the expenses included in the social overall planning can be subsidized for a certain period of time and a certain amount according to the local financial situation.

\subsection{Improve the retirement age policy}

In terms of retirement age restriction policy, flexible employees and full-time regular employees should enjoy the same treatment. Most of the urban female workers with flexible employment have been engaged in manual labor and simple technical work for a long time, with poor working environment and high labor intensity, and there is no big difference with female managers and technical workers. Their retirement age should be the same as that of female workers, that is, 50 years old. In addition, for those who have reached the age of 15 but have not paid the endowment insurance premium, the principle of moderation should be adopted, and those who have reached the age of 63 should not be allowed to pay the endowment insurance premium indefinitely.

\section{Conclusion}

At present, with the development of economy and technology, some new jobs, such as online car hailing, delivery boy and courier, have further expanded the scale of flexible employment. At present, after the impact of the epidemic, China's medical security is gradually improving; from the takeaway baby brother injury incident to the reform of work-related injury insurance, most of China's social security system for flexible employment is improving, but the reform of pension security is backward due to the large time span and low urgency.

There are some institutional problems, such as the heavy burden of endowment insurance payment, the insufficient publicity service of endowment insurance, the difficulty in extending the transfer of endowment insurance relationship, the lack of relevant legal protection of endowment insurance, the inability to make up payment for older people, the cumbersome steps of obtaining state subsidies, and the characteristics of flexible employment personnel increase the difficulty of insurance work, and the unit of flexible employment personnel is not willing to participate This paper analyzes the contradictions among the payment of endowment insurance, the lack of awareness of endowment insurance policy, and the low degree of organization. This paper puts forward some suggestions, such as implementing flexible multi-level old-age security,further improving the transition of oldage insurance relationship,improving the relevant work of the government, increasing national support, and improving the retirement age policy. 


\section{Acknowledgment}

I am very grateful to my tutor. No matter the topic selection, outline preparation, content modification and a series of thesis writing work, my tutor gave me careful guidance and gave me a lot of help, and clarified the writing ideas and operation methods for me. Thank my parents for always supporting my studies and giving me confidence. At the same time, I would like to thank the author of the article cited in this article for giving me abundant information to complete this article.

\section{References}

1. Li Zhuozhuo. (2020) On the protection of the rights and interests of non self employed workers in the platform economy [J]. Modern marketing (Business Edition), 82-83.

2. Liu Junyi, Han Yipeng. (2019) Improving the labor and social security system to promote the healthy development of flexible employment [J]. Economist, $36-37+39$.

3. Li Zhenxing. (2017) Research on endowment insurance payment of flexible employees in older cities and towns -- Taking Fengxian County of Xuzhou City as an example [J]. Journal of the Party School of Nanjing municipal Party committee, 70-75.

4. Liu Saite. (2017) Research on endowment insurance system for urban flexible employees [J]. Labor and social security world , 17-18.

5. Zuo Li. (2020) Positioning of labor relations and protection of rights and interests in the Internet economy [J]. Journal of Mudanjiang University , 5-9.

6. Sun Tao. (2015) Research on social pension of flexible employment floating population -- Based on the investigation of Sichuan and Zhejiang [J]. Journal of Northwest Normal University (SOCIAL SCIENCE EDITION) , 16-23. 